\title{
Thermodynamic Analysis of Combined Vapor Compression and Vapor Absorption Refrigeration System
}

\author{
AAMIR SHAIKH*, IKRAM KHURSHID*, ABDUL GHAFOOR MEMON*, AAKASH DEEP*, AND \\ TAHWER HUSSAIN*
}

RECEIVED ON 09.01.2017 ACCEPTED ON 29.05.2017

\begin{abstract}
Two of the popular refrigeration cycles, VC (Vapor Compression), and VA(Vapor Absorption) are used extensively for refrigeration purposes. In this paper, a system is proposed that works using both cycles powered by an IC (Internal Combustion) engine, where mechanical energy is used to run the VC cycle while exhaust gasses are used to operate the VAcycle. The VC cycle works on R12 refrigerant while $\mathrm{LiBr}-\mathrm{H}_{2} \mathrm{O}$ combination is selected for operation of VAcycle. Firstly, the refrigeration system is modeled, followed by a parametric study to investigate the impacts of various operating parameters on the system performance. The results exhibit that for maximum chilling and overall performance, the condenser and evaporator pressures in the VC cycle are obtained as 710 and $340 \mathrm{kPa}$, respectively, whereas generator and absorber temperatures in VAcycle are 85 and $20^{\circ} \mathrm{C}$, respectively.
\end{abstract}

Key Words: Vapour Compression Cycle, Vapour Absorption Cycle, Engine Waste Heat, Thermodynamic Analysis

\section{INTRODUCTION}

$\underbrace{1}$ nergy resources must be utilized in the most effective way to cope up with the increasing energy demands. In the present era, energy consumption is augmenting due to rapid growth in industrialization, technological developments, emerging population, and enhancements in living standards. The electricity production has doubled globally during the past 22 years.

With cooling effect as a product for human comfort and industrial processes, different types of refrigeration cycles are used, requiring various forms of energy inputs. The VC cycle that needs a high grade of energy to operate offers high COP (Coefficient of Performance).
A considerable amount of energy is utilized in the compression of refrigerant. The operating cost of a VC system is greater than a VA system. The VC refrigeration cycle is the most widely used refrigeration cycle. The VA system is commonly used, where there is the availability of low-grade energy, this system can also utilize energy from exhaust heat sources or steam. These systems require less maintenance and are noiseless in comparison to power-driven systems, also proven to be environmentally-friendly as compared to other systems [1]. Energy management of HVAC (Heating, Ventilating and Air Conditioning) systems is the chief concern for

* Department of Mechanical Engineering, Mehran University of Engineering \& Technology, Jamshoro

Mehran University Research Journal of Engineering \& Technology, Volume 36, No. 3, July, 2017 [p-ISSN: 0254-7821, e-ISSN: 2413-7219] 
buildings and other applications. Electrical power consumption in HVAC is the highest among other services and installations required for the building. One of the aspects of HVAC is air conditioning, which maintains the proper humidity of theair, cleans the air from dust and other particles and maintains the desired temperature, keeping ventilation in check. Chilled water systems are often used in buildings for thermal comfort, enhancing their performance results in the immediate effect of energy saving. These systems are getting popular in demand as the number of high-rise buildings are increasing. Various methods for optimal performance are being studied for designing energy efficient systems [2]. Various solar-assisted VA and cascade refrigeration cycles have been studied with different working fluid combinations [3-5]. A number of researchwork is devoted to thermodynamic, economic and environmental analyses of VA refrigeration cycles [6], ejector-based cascade refrigeration cycle [7] and $\mathrm{VC}$ cascade cycle with different refrigerant combinations [8]. A general theoretical analysis is performed on a VC-VA cascade system with different fluids without considering the particular source of operation [9].

The literature review related to the cascade refrigeration shows a limited analysis of cascade refrigeration systems considering only components of refrigeration cycles, ignoring the prime movers which operate the systems. In this paper, a novel cascade refrigeration system is proposed that is processed for energy analysis by including a gas engine as the prime mover along with the refrigeration cycles. The combined system consists of a gas engine, refrigerated space, VC cycle and a VA cycle with a heat exchanger. The system is modeled and analyzed with parametric-based energy concepts using EES (Engineering Equation Solver) software. The cooling capacity and overall system performance are considered as the dependent variables while condenser and evaporator pressures of $\mathrm{VC}$ cycle and generator and absorber temperatures of VA cycle are nominated as independent variables.

\section{WORKING OF PROPOSED MODEL}

Fig. 1 exhibits the schematic of proposed model. The primary source of power in the proposed system is provided by an IC engine which runs the compressor of $\mathrm{VC}$ cycle while exhaust gasses are used to operate the VA cycle by surrendering the heat to the generator. The evaporators of both refrigeration cycles absorb heat from the chilled water used for cooling purposes. The chilled water after absorbing heat from the refrigerated space enters the evaporator of VA cycle for cooling corresponding to state 13 and leaves at a lower temperature with state 14 . Afterward, water enters the evaporator of VC cycle for further cooling. The chilled water finally enters the refrigerated space at state 15 . The VC cycle is operated with $\mathrm{R} 12$ refrigerant whereas VA cycle works on a $\mathrm{LiBr}-\mathrm{H}_{2} \mathrm{O}$ solution $\left(\mathrm{H}_{2} \mathrm{O}\right.$ as refrigerant and $\mathrm{LiBr}$ as absorbent). R12, after gets compressed in the compressor, passes through a condenser where it surrendered heat to the surrounding or cooling water and routed back to the evaporator through throttling valve. In VA cycle, the refrigerant is separated in the generator and passes through the condenser, throttling valve, vaporator, and absorbs in the $\mathrm{LiBr}-\mathrm{H}_{2} \mathrm{O}$ solution already present in the absorber. The rich solution produced in the absorber is then pumped to the generator, and the weak solution from the generator is throttled back to the absorber. The proposed system can be adopted for air conditioning the buildings of residential, commercial and industrial sites.

\section{THERMODYNAMIC MODELLING}

In this section, thermodynamic modeling of the system is presented which is mainly based on the continuity equation and first law equation for control volumes as given below:

$$
\sum_{\mathrm{i}} \dot{\mathrm{m}}-\sum_{\mathrm{e}} \dot{\mathrm{m}}=\frac{\mathrm{dm}_{\mathrm{cv}}}{\mathrm{dt}}
$$


$\dot{\mathrm{Q}}-\dot{\mathrm{W}}+\sum_{\mathrm{i}} \dot{\mathrm{m}}(\mathrm{h}+\mathrm{ke}+\mathrm{pe})-\sum_{\mathrm{e}} \dot{\mathrm{m}}(\mathrm{h}+\mathrm{ke}+\mathrm{pe})=\frac{\mathrm{dE}_{\mathrm{cv}}}{\mathrm{dt}}$

To apply each of these equations to model different components of the system, following assumptions are made:

(1) All processes are under steady-state condition.

(2) The change in kinetic energy and change in potential energy of the flowing fluids are negligible.

(3) The compressor work of VC cycle is isentropic.

(4) The pressure drop in fluids flowing through condensers, evaporators, heat exchangers, and pipes is insignificant.

(5) The refrigerants at the exit of condensers and evaporators are saturated liquid and saturated vapors, respectively.

(6) The pump work is negligible.

(7) Power input to the refrigerant in the compressor is $50 \mathrm{~kW}$ (commercial availability for medium-to-large scale HVAC systems).
Saturation temperature in condenser and evaporator of $\mathrm{VC}$ cycle is 30 and $0^{\circ} \mathrm{C}$, respectively, whereas in VA cycle these are 34 and $8^{\circ} \mathrm{C}$, respectively. (These temperature values are taken for theoretical analysis of the system in order to avoid freezing of water in the evaporators and ensuring effective heat exchange between the working fluids and the sinks.)

(10) The efficiency of combined engine/compressor is $25 \%$, which includes all mechanical, transmission and thermodynamic losses.

Heat supplied from engine exhaust is $50 \%$ of the energy input from the fuel supplied to the engine, which occurs in practice due to inherent deficiencies during the fuel combustion and heat exchange in the commercially available heat exchangers.

Chilled water inlets at $18^{\circ} \mathrm{C}$, which is theoretically been kept constant to calculate the cooling capacity of the system.

Now with these assumptions, Table 1 is generated which exhibits the application of basic equations to various system components. transfer to the surroundings is negligible.

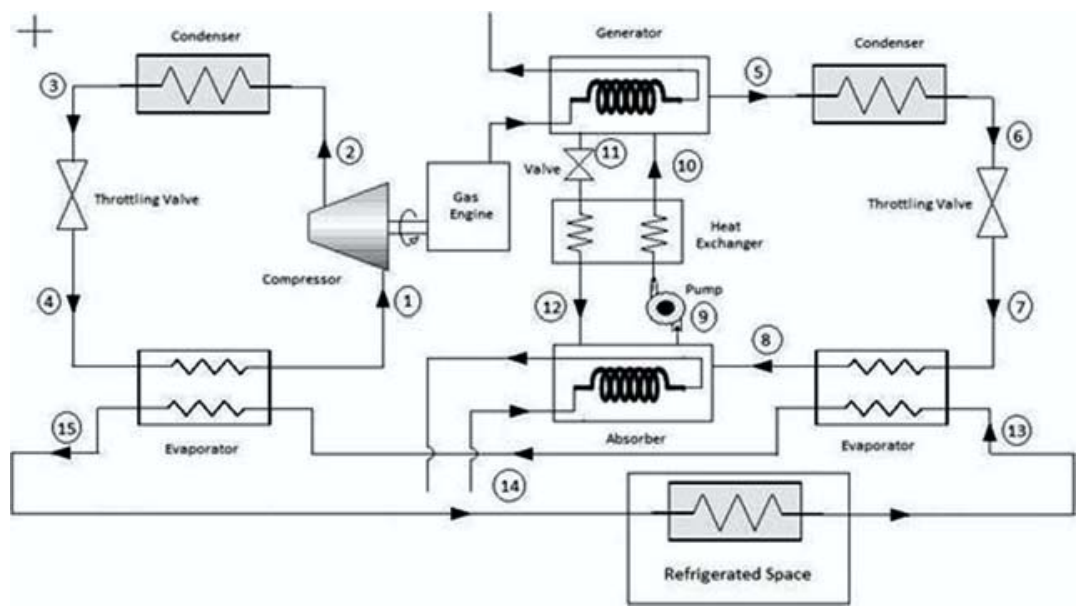

FIG. 1. SCHEMATIC OF THE PROPOSED MODEL 


\subsection{Performance of Combined System}

The thermal efficiency of the IC engine is given as:

$\eta_{\text {eng }}=\frac{\dot{\mathrm{W}}_{\text {eng }}}{\dot{\mathrm{Q}}_{\text {fuel }}}$

The generator of VA cycle is extracting $50 \%$ of the heat energy provided to the engine by fuel, according to assumption 11 above. Therefore, heat received by generator is given as:

$\dot{\mathrm{Q}}_{\text {eng }}=0.5 \times \dot{\mathrm{Q}}_{\text {fuel }}$

CoP of the cycles is given by:

$$
\mathrm{COP}_{\mathrm{VC}}=\frac{\dot{\mathrm{Q}}_{\mathrm{evp}, \mathrm{VC}}}{\dot{\mathrm{W}}_{\mathrm{comp}}}
$$

TABLE 1. MODELING FORMULATIONS OF DIFFERENT SYSTEM COMPONENTS

\begin{tabular}{|c|c|c|}
\hline \multicolumn{3}{|c|}{ Vapor Compression System } \\
\hline Component & Mass Balance & Energy Balance \\
\hline Compressor & $\dot{\mathrm{m}}_{2}=\dot{\mathrm{m}}_{1}$ & $\dot{\mathrm{W}}=\dot{\mathrm{m}}_{1}\left(\mathrm{~h}_{2}-\mathrm{h}_{1}\right)$ \\
\hline Throttling Valve & $\dot{\mathrm{m}}_{4}=\dot{\mathrm{m}}_{3}$ & $\mathrm{~h}_{4}=\mathrm{h}_{3}$ \\
\hline Condenser & $\dot{\mathrm{m}}_{3}=\dot{\mathrm{m}}_{2}$ & $\dot{\mathrm{Q}}_{\mathrm{cnd}, \mathrm{VC}}=\dot{\mathrm{m}}_{1}\left(\mathrm{~h}_{2}-\mathrm{h}_{3}\right)$ \\
\hline Evaporator & $\dot{\mathrm{m}}_{1}=\dot{\mathrm{m}}_{4}$ & $\begin{array}{c}\dot{\mathrm{Q}}_{\mathrm{evp}, \mathrm{VC}}=\dot{\mathrm{m}}_{1}\left(\mathrm{~h}_{1}-\mathrm{h}_{4}\right) \\
\dot{\mathrm{Q}}_{\mathrm{evp}, \mathrm{VC}}=\dot{\mathrm{m}}_{\mathrm{cw}} \mathrm{C}_{\mathrm{p}}\left(\mathrm{h}_{14}-\mathrm{h}_{15}\right)\end{array}$ \\
\hline \multicolumn{3}{|c|}{ Vapor Absorption System } \\
\hline Component & Mass Balance & Energy Balance \\
\hline Generator & $\begin{array}{c}\dot{\mathrm{m}}_{10}=\dot{\mathrm{m}}_{11}+\dot{\mathrm{m}}_{5} \text { (solution) } \\
\dot{\mathrm{m}}_{10} \mathrm{x}_{10}=\dot{\mathrm{m}}_{11}+\dot{\mathrm{m}}_{5} \mathrm{x}_{11}(\mathrm{LiBr})\end{array}$ & $\dot{\mathrm{Q}}_{\mathrm{gen}}=\dot{\mathrm{m}}_{11} \mathrm{~h}_{11}+\dot{\mathrm{m}}_{5} \mathrm{~h}_{5}-\dot{\mathrm{m}}_{10} \mathrm{~h}_{10}$ \\
\hline Absorber & $\begin{array}{c}\dot{\mathrm{m}}_{9}=\dot{\mathrm{m}}_{11}+\dot{\mathrm{m}}_{8} \text { (solution) } \\
\dot{\mathrm{m}}_{12} \mathrm{x}_{12}=\dot{\mathrm{m}}_{11}+\dot{\mathrm{m}}_{9} \mathrm{x}_{9}(\mathrm{LiBr})\end{array}$ & $\dot{\mathrm{Q}}_{\mathrm{abs}}=\dot{\mathrm{m}}_{11} \mathrm{~h}_{11}+\dot{\mathrm{m}}_{8} \mathrm{~h}_{8}-\dot{\mathrm{m}}_{9} \mathrm{~h}_{9}$ \\
\hline Pump & $\begin{array}{c}\dot{\mathrm{m}}_{10}=\dot{\mathrm{m}}_{9}(\text { solution }) \\
\dot{\mathrm{m}}_{10} \mathrm{x}_{10}=\dot{\mathrm{m}}_{9} \mathrm{x}_{9}(\mathrm{LiBr})\end{array}$ & $\dot{\mathrm{W}}=0$ \\
\hline Throttling Valve & $\begin{aligned} \dot{\mathrm{m}}_{11} & =\dot{\mathrm{m}}_{12} \\
\dot{\mathrm{m}}_{11} \mathrm{x}_{11} & =\dot{\mathrm{m}}_{12} \mathrm{x}_{12}\end{aligned}$ & $\mathrm{~h}_{6}=\mathrm{h}_{7}$ \\
\hline Heat Exchanger & $\begin{array}{c}\dot{\mathrm{m}}_{9}+\dot{\mathrm{m}}_{11}=\dot{\mathrm{m}}_{10}+\dot{\mathrm{m}}_{12} \text { (solution) } \\
\dot{\mathrm{m}}_{9} \mathrm{x}_{9}+\dot{\mathrm{m}}_{11} \mathrm{x}_{11}=\dot{\mathrm{m}}_{10} \mathrm{x}_{10}+\dot{\mathrm{m}}_{12} \mathrm{x}_{12}(\mathrm{LiBr})\end{array}$ & $\dot{\mathrm{m}}_{11}\left(\mathrm{~h}_{11}-\mathrm{h}_{12}\right)=\dot{\mathrm{m}}_{9}\left(\mathrm{~h}_{10}-\mathrm{h}_{9}\right)$ \\
\hline Evaporator & $\dot{\mathrm{m}}_{8}=\dot{\mathrm{m}}_{7}$ & $\begin{array}{c}\dot{\mathrm{Q}}_{\mathrm{evp}, \mathrm{VA}}=\dot{\mathrm{m}}_{7}\left(\mathrm{~h}_{7}-\mathrm{h}_{8}\right) \\
\dot{\mathrm{Q}}_{\mathrm{evp}, \mathrm{VA}}=\dot{\mathrm{m}}_{\mathrm{cw}} \mathrm{C}_{\mathrm{p}}\left(\mathrm{h}_{13}-\mathrm{h}_{14}\right)\end{array}$ \\
\hline Condenser & $\dot{\mathrm{m}}_{6}=\dot{\mathrm{m}}_{5}$ & $\dot{\mathrm{Q}}_{\mathrm{cnd}, \mathrm{VA}}=\dot{\mathrm{m}}_{5}\left(\mathrm{~h}_{5}-\mathrm{h}_{6}\right)$ \\
\hline Throttling Valve & $\dot{\mathrm{m}}_{7}=\dot{\mathrm{m}}_{6}$ & $\mathrm{~h}_{7}=\mathrm{h}_{6}$ \\
\hline
\end{tabular}

Mehran University Research Journal of Engineering \& Technology, Volume 36, No. 3, July, 2017 [p-ISSN: 0254-7821, e-ISSN: 2413-7219] 
$\mathrm{COP}_{\mathrm{VA}}=\frac{\dot{\mathrm{Q}}_{\mathrm{evp}, \mathrm{VA}}}{\dot{\mathrm{Q}}_{\mathrm{gen}}}$

The heat absorbed by chilled water from the refrigerated space (i.e. cooling capacity) is given as:

$$
\dot{\mathrm{Q}}_{\text {capacity }}=\dot{\mathrm{m}}_{\mathrm{cw}} \mathrm{C}_{\mathrm{p}}\left(\mathrm{T}_{13}-\mathrm{T}_{15}\right)
$$

Equation (7) represents heat carrying capacity by chilled water while flowing through the refrigerated space which may be applied for space cooling, refrigeration of foodstuffs, etc.

The overall performance of the combined system can be determined from

$$
\mathrm{Op}=\frac{\dot{\mathrm{Q}}_{\mathrm{evp}, \mathrm{VC}}+\dot{\mathrm{Q}}_{\mathrm{evp}, \mathrm{VA}}}{\dot{\mathrm{Q}}_{\text {fuel }}}
$$

\section{MODEL VALIDATION}

Results for heat transfers and COP of VA cycle as reported by Anand and Kumar [3], Kaushik and Arora [10], and Sarkar and Basu [11] are compared with the simulated values in order to validate the model. Fig. 2 presents a

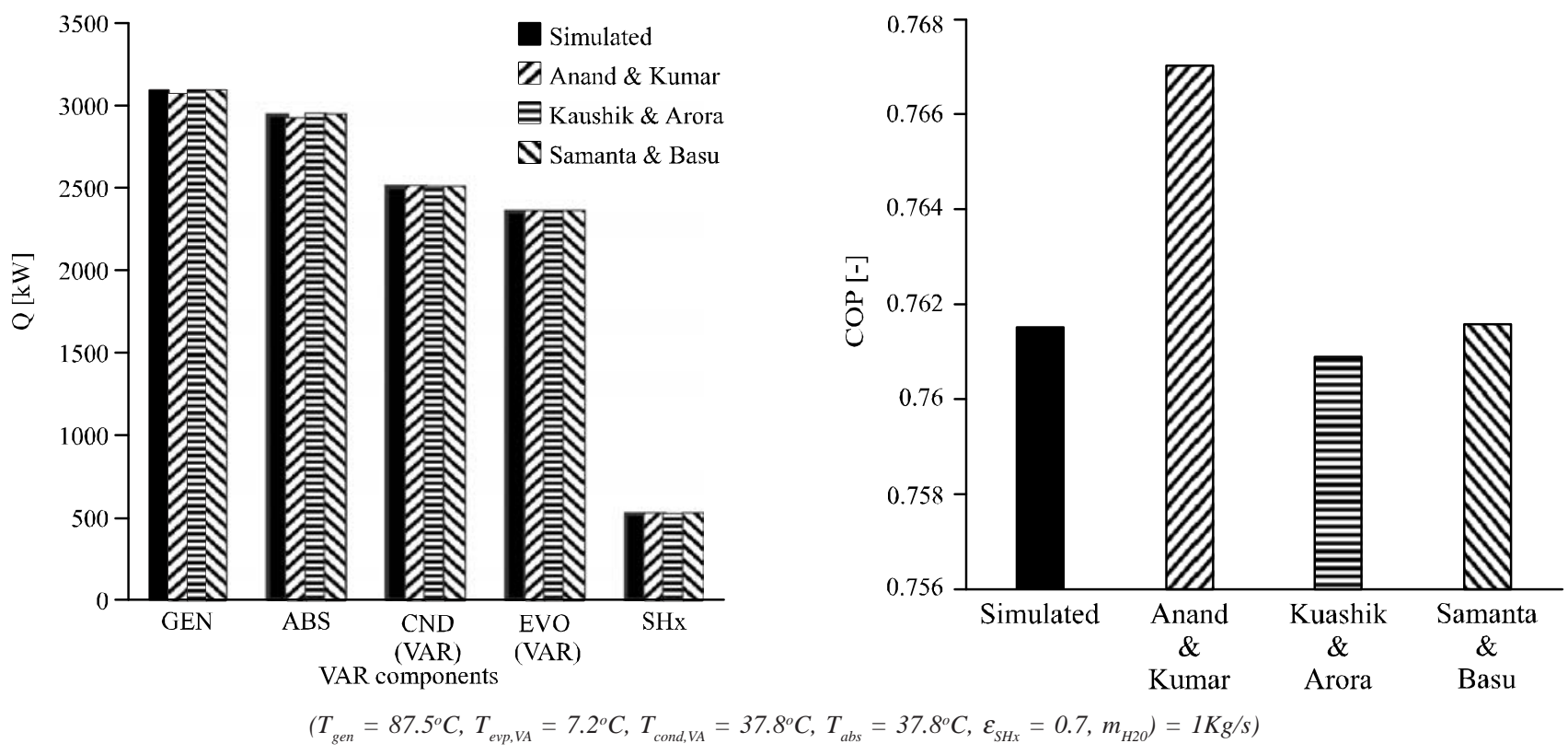

FIG. 2. VA-MODEL VALIDATION

comparison of the simulated and reported heat transfer rates obtained for the generator, absorber, condenser, evaporator and solution heat exchanger and $\mathrm{COP}$ of the cycle. An excellent agreement is obtained, with the largest average difference in the magnitudes of heat transfer rate being less than $0.35 \%$. The consensus in the magnitudes of COP is also significant, which has a mean difference less than $0.3 \%$.

\section{RESULTS AND DISCUSSION}

In this section, results of the parametric analysis have been discussed. The effects of condenser and evaporator pressures of $\mathrm{VC}$ cycle and the generator and absorber temperatures of VA cycle on the system's overall performance and cooling capacity have been investigated. Table 2 indicates the operating parameters maintained in the base case and their ranges for the parametric study. The base case values refer to those values of operating parameters which usually prevails during a normal operation of the system. But in actual practice, these parameters may vary due to many reasons, which is the case considered in the parametric study in given ranges of values.

Mehran University Research Journal of Engineering \& Technology, Volume 36, No. 3, July, 2017 [p-ISSN: 0254-7821, e-ISSN: 2413-7219] 


\subsection{Effect of Condenser and Evaporator Pressures of VC Cycle}

The effects of condenser pressure on the cooling capacity and overall performance of the combined system at different evaporator pressures are exhibited in Figs. 3-4, respectively. It is evident from Figs. 3-4 that cooling capacity and overall performance increase with a decrease in the condenser pressure and an increase in the evaporator pressure. An additional amount of refrigerating effect (and cooling capacity) is produced in the VC evaporator, equivalent to the additional heat removal from the refrigerant required in the condenser when condenser pressure decreases. It is due to the reason that the latent heat of fluids normally increases with a decrease in the pressure, which can be quantified by referring Fig. 5 that exhibits Ph-diagram of R12. The decline in condenser pressure also reduces the compressor work, which requires less amount of fuel for the engine. Hence, the overall impact of the reduction in the condenser pressure of $\mathrm{VC}$ cycle is increased in the cooling capacity and performance of the system. In the case when evaporator pressure increases, the cooling capacity increases due to increase in the latent heat of vaporization of the refrigerant, which can be quantified by referring Fig.5. Concurrently, the compressor work decreases with an increase in the evaporator pressure, thereby increases the overall performance of the system.

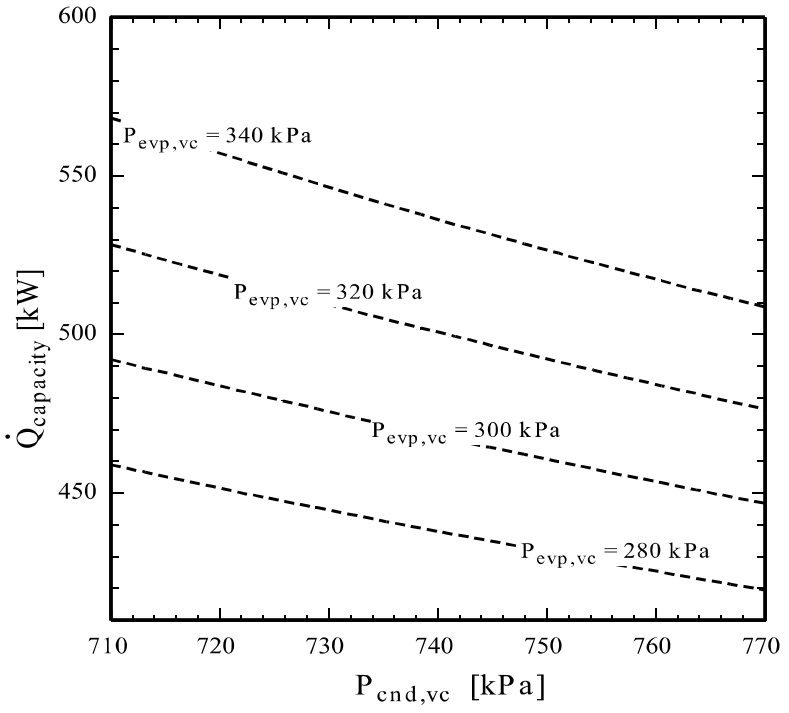

FIG. 3. EFFECT OF CONDENSER AND EVAPORATOR PRESSURES OF VC CYCLE ON COMBINED SYSTEM'S COOLING CAPACITY

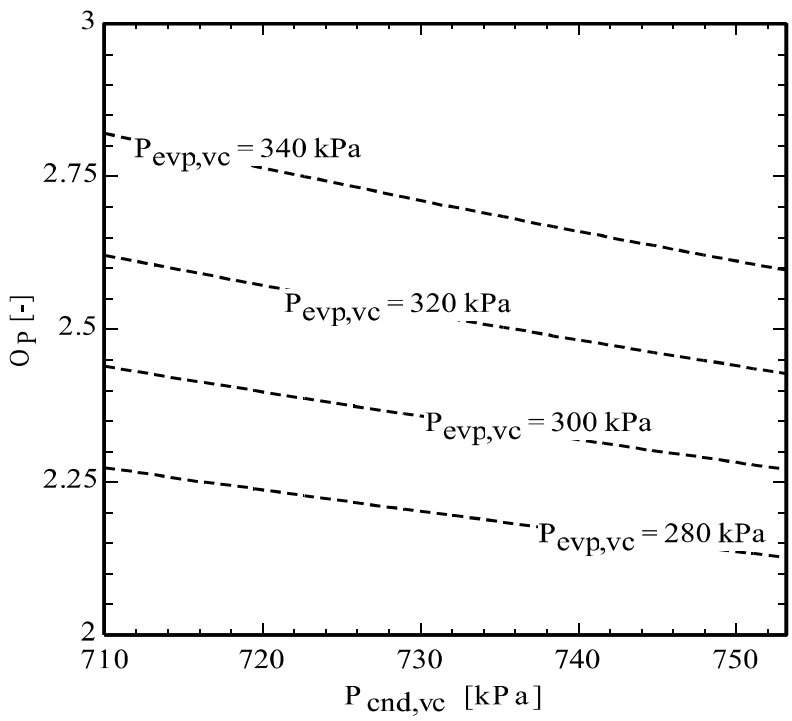

FIG. 4. EFFECT OF CONDENSER AND EVAPORATOR PRESSURES OF VC CYCLE ON COMBINED SYSTEM'S OVERALL PERFORMANCE

TABLE 2. VALUES OF OPERATING PARAMETERS

\begin{tabular}{|c|c|c|c|}
\hline No. & Operating Parameter & Base Case Value & Variation Range \\
\hline 1. & Condenser pressure of VC cycle (Pcond,VC) & $744.4 \mathrm{kPa}$ & $710-770 \mathrm{kPa}$ \\
\hline 2. & Evaporator pressure of VC cycle (Pevp,VC) & $308.3 \mathrm{kPa}$ & $280-340 \mathrm{kPa}$ \\
\hline 3. & Condenser temperature of VA cycle (Pcond,VA) & $34 \mathrm{oC}$ & Constant \\
\hline 4. & Evaporator temperature of VA cycle (Tevp,VA) & $80 \mathrm{C}$ & $20-40 \mathrm{oC}$ \\
\hline 5. & Absorber temperature (Tabs) & $40 \mathrm{oC}$ & $80-115 \mathrm{oC}$ \\
\hline 6. & Generator temperature (Tgen) & $85 \mathrm{oC}$ & Constant \\
\hline 7. & Mass flow rate chilling water & $10 \mathrm{~kg} / \mathrm{s}$ & \\
\hline
\end{tabular}

Mehran University Research Journal of Engineering \& Technology, Volume 36, No. 3, July, 2017 [p-ISSN: 0254-7821, e-ISSN: 2413-7219] 


\subsection{Effect of Generator and Absorber Temperatures of VA Cycle}

Figs. 6-7 exhibit the effects of generator and absorber temperatures on cooling capacity and overall performance of the combined system, respectively, which reflect a similar trend in variation. The cooling capacity and overall performance increase with a decrease in the absorber temperature while decrease initially then starts to grow with an increase in the generator temperature. As the reaction in the absorber is exothermic, a lower temperature increases the absorbing capacity of the absorbent for the refrigerant, which causes generation of the refrigerant in the generator at a higher rate. It results in an increase in the refrigerating effect and overall performance. Similarly, higher generator temperatures cause same effects since more refrigerant is generated in the generator. Notably, it is shown in Figs. 6-7 that both quantities decrease with increase in the generator temperature up to $105^{\circ} \mathrm{C}$ and then starts to grow.

\section{CONCLUSION}

A combined VC-VA refrigeration system powered by IC engine for refrigeration applications is proposed. The $\mathrm{VC}$ is by far the most widely used refrigeration system due to high performance with absorption units of importance if a cheap source of thermal energy is available. The significance of the proposed model is to obtain both these benefits with the help of an IC engine whose mechanical energy is transferred directly to the VC cycle while its waste heat to the VAcycle. A thermodynamic model of the system was developed from

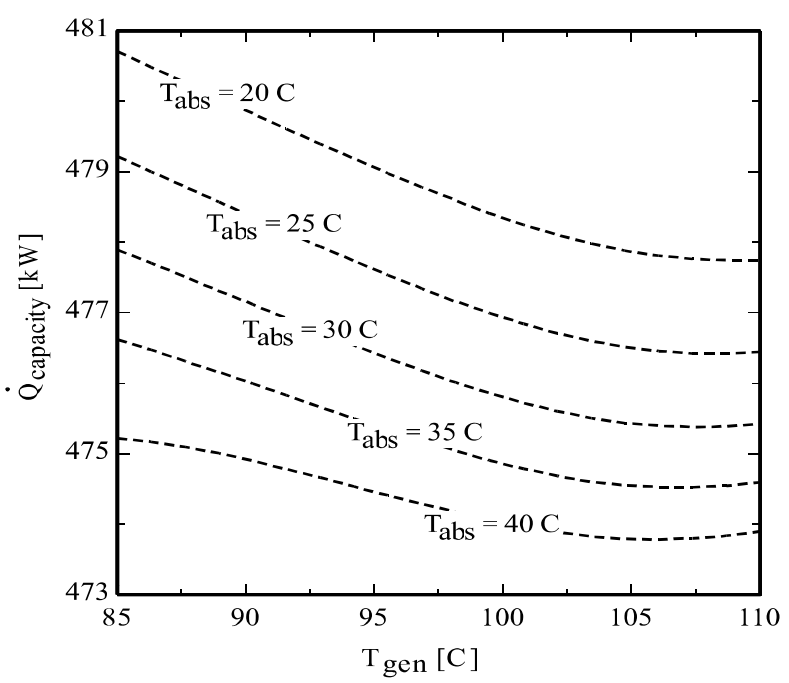

FIG. 6. EFFECT OF GENERATOR AND ABSORBER TEMPERATURES OF VA CYCLE ON COMBINED SYSTEM'S COOLING CAPACITY

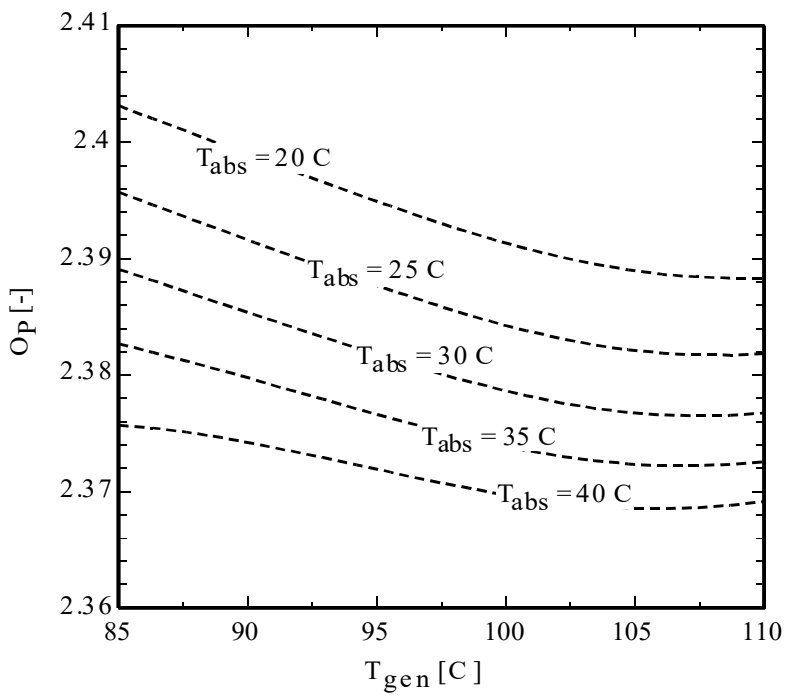

FIG. 7. EFFECT OF GENERATOR AND ABSORBER TEMPERATURES OF VA CYCLE ON COMBINED SYSTEM'S OVERALL PERFORMANCE

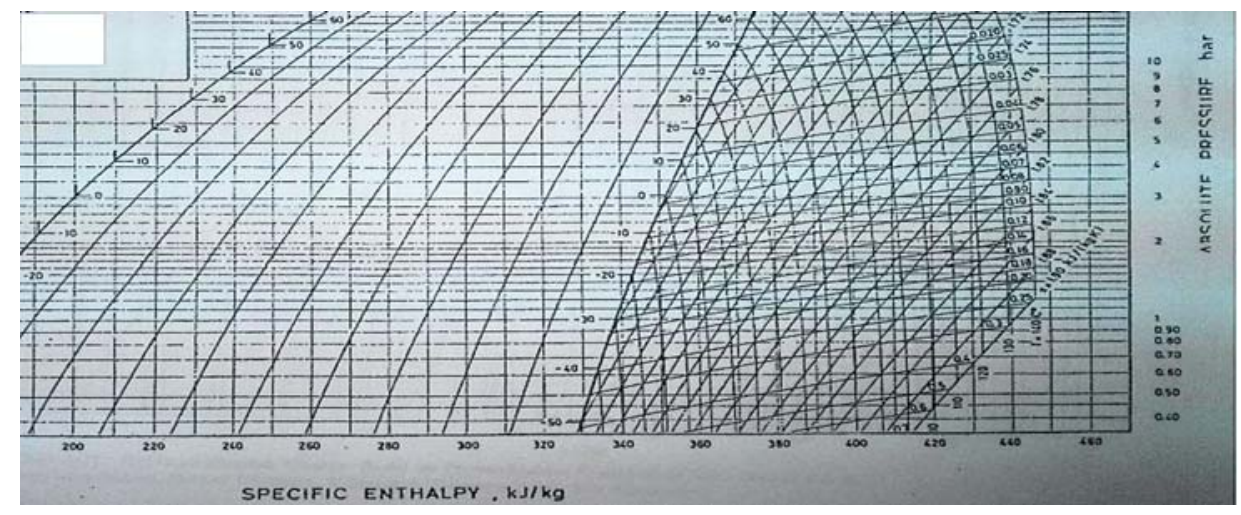

FIG. 5. PH-DIAGRAM OF R12 
the first law point of view. The developed model admirably predicts results available in the literature. The energy-based parametric analysis was performed to assess the effects of condenser and evaporator pressures of $\mathrm{VC}$ cycle and generator and absorber temperatures of VA cycle on the system cooling capacity and overall performance. According to the results, cooling capacity and overall performance increase with a decrease in the condenser pressure and increase in the evaporator pressure of $\mathrm{VC}$ cycle while both decrease with absorber temperature and generator temperature of VA cycle until some minimum values and increase afterward. Furthermore, the system attained optimal cooling capacity and overall performance with $570 \mathrm{~kW}$ and 2.83 , respectively, corresponding to $\mathrm{VC}$ cycle's condenser and evaporator pressures of 710 and $340 \mathrm{kPa}$, respectively under the base-case operating values. Similarly, with respect to the VA cycle's generator and absorber temperatures, maximum capacity, i.e. $480 \mathrm{~kW}$ and overall performance, i.e. 2.4 were attained corresponding to 85 and $20^{\circ} \mathrm{C}$, respectively with base-case conditions.

\section{NOMENCLATURE}

$\begin{array}{cl}\dot{\mathrm{m}} & \text { Mass flow rate of fluids. } \\ \mathrm{x} & \text { Concentration of } \mathrm{LiBr} \text { in } \mathrm{LiBr}-\mathrm{H} 2 \mathrm{O} \text { solution. } \\ \mathrm{T} & \text { Temperature of fluids. } \\ \mathrm{h} & \text { Enthalpy of fluids. } \\ \dot{\mathrm{Q}} & \text { Heat transfer rate. } \\ \dot{\mathrm{W}} & \text { Work transfer rate. }\end{array}$

\section{ACKNOWLEDGEMENT}

The authors highly acknowledge the assistance provided by the Department of Mechanical Engineering, Mehran University of Engineering \& Technology, Jamshoro, Pakistan, in carrying out the current piece of research work.

\section{REFERENCES}

[1] Sharma, A., Mishra, B.K., Dinesh, A., and Misra, A., "Configuration of a $2 \mathrm{~kW}$ Capacity Absorption Refrigeration System Driven by Low Grade Energy Source", International Journal of Metallurgical \& Materials Science and Engineering, Volume 2, No. 4, pp. 1-9, 2012.
Ma, Z.J., and Wang, S.W., "An Optimal Control Strategy for Complex Building Central Chilled Water Systems for Practical and Real-Time Applications”, Build Environ, Volume 44, pp. 1188-98, 2009.

[3] Anand, D.K., and Kumar, B., "Absorption Machine Irreversibility using New Entropy Calculations", Solar Energy, Volume 39, No. 3,pp. 243-256, 1987.

[4] Boyaghchi, F.A., Mahmoodnezhad, M., and Sabeti, V., "Exergoeconomic Analysis and Optimization of a Solar Driven Dual Evaporator Vapor Compression-Absorption Cascade Refrigeration System using Water/ CuONanofluid", Journal of Cleaner Production, Volume 139, pp. 970-985, 2016.

[5] Wang, L., Ma, A., Tan, Y., Cui, X., and Cui, H., "Study on Solar-Assisted Cascade Refrigeration System", Energy Procedia, Volume16, pp.1503-1509, 2012.

[6] Jain, V., Sachdeva, G., Kachhwaha, S.S., and Patel, "Thermo-Economic and Environmental Analyses Based Multi-Objective Optimization of Vapor CompressionAbsorption Cascaded Refrigeration System using NSGAII Technique", Energy Conversion and Management, Volume 113, pp. 230-242, 2016

[7] Megdouli, K., Tashtoush, B.M., Nahdi, E., Elakhdar, M., Kairouani, L., Mhimid, A., "Thermodynamic Analysis of a Novel Ejector Cascade Refrigeration Cycles for Freezing Process Applications and Air-Conditioning", International Journal of Refrigeration, Volume 70, pp. 108-118, 2016.

[8] Sun, Z., Liang, Y., Liu, S., Ji, W., Zang, R., Liang, R., and Guo, Z., "Comparative Analysis of Thermodynamic Performance of a Cascade Refrigeration System for Refrigerant Couples R41/R404A and R23/R404", Applied Energy, Volume 184, pp. 19-25, 2016.

[9] Cimsit, C., and Ozturk, I.T., "Analysis of CompressionAbsorption Cascade Refrigeration Cycles", Applied Thermal Engineering, Volume 40, pp. 311-317, 2012.

[10] Kaushik, S.C., and Arora, A., "Energy and Exergy Analysis of Single Effect and Series Flow Double Effect WaterLithium Bromide Absorption Refrigeration Systems", International Journal of Refrigeration, Volume 32, No. 6, pp. 1247-1258, 2009.

[11] Sarkar, D.N., and Basu, D.N., "Thermodynamic Analysis of the Effect of Generator Temperature on the Performance of a Single-Effect Absorption Refrigeration Cycle", Proceedings of 2nd International Conference on Advances in Mechanical Engineering and its Interdisciplinary Areas, pp. 136-143, Kolaghat, India, January 2-4, 2015.

[12] Kalogirou, S., Florides, G., Tassou, S., and Wrobel, L., "Design and Construction of a Lithium Bromide Water Absorption Refrigerator" Clima 2000/Napoli 2001 World Congress - Napoli (I), 15-18 September, 2001.

[13] Mahendru, P., Agrawal, S.K., and Pachorkar, P., "Steady State Analysis of Vapor Absorption Refrigeration System using $\mathrm{LiBr}-\mathrm{H} 2 \mathrm{O}$ as a Refrigerant", International Journal of Emerging Technology and Advanced Engineering, Volume 2, No. 9, pp. 328-332, 2012.

[14] Cengel, Y.A., and Boles, M.A., "Thermodynamics: An Engineering Approach", Edition 5, McGraw-Hill. 